\title{
ESTABILIDADE DE EMULSÕES DE CARNE OBTIDAS EM LABORATÖRIO*
}

\author{
MURILO Graner ** \\ Natal B. Meira Barros *** \\ Roberto S. DE Moraes ****
}

\begin{abstract}
RESUMO
A elaboração de pequenas quantidades de emulsăo de carne, em laboratório, pode ser de grande valia no ensino de ciência e tecnologia da carne e no desenvolvimento de certos tipos de pesquisa, por razões de ordem prática e económica. No presente trabalho fol estudada a influência de alguns fatores sobre a estabilidade de emulsões de carne obtidas em pequeno triturador de alimentos, tipo «cutter», de mesa, com carne magra bovina e gordura suina. Nas condições dos ensaios realizados, verificou-se a possibilidade de serem obtidos sistemas estáveis, tendo o pH da carne ou da emulsão sido fator limitante. A adição prévia de sal comum à carne não foi suficiente para a estabilidade das emulsões. Quanto à composição química da matéria-prima, a relação umidade/proteina da carne magra do pescoço foi significativamente inferior a da carne magra da paleta.
\end{abstract}

\section{INTRODUÇAOO}

Segundo BECHER (1965), emulsão é um sistema heterogêneo no qual existe pelo menos uma fase líquida, na forma de gotículas cujo diâmetro é maior que $0,1 \mathrm{~nm}$, dispersa em outro líquido. Esse diâmetro pode variar até $50 \mathrm{~nm}$ (Osipow, citado por SAFFLE, 1968). No caso da chamada emulsão de carne, a fase dispersa consiste em partículas de gordura contidas em fase aquosa onde se encontram, além de outras substâncias, proteínas solúveis de origem muscular (WILSON, 1960 a; SWIFT, 1965; SAFFLE, 1968). Não se trata, porém, de uma emulsão verdadeira, mas de um sistema em que as partículas de gordura apresentam grande variação de tamanho, podendo ser, inclusive, bem maiores que $50 \mathrm{~nm}$.

Desenvolvido com a contribuição material do Convênio OSU/USAID/ESALQ e da FAPESP.

* Departamento de Tecnologia Rural da ESALQ.

*** Ex-Aluno - Monitor do Departamento de Tecnologia Rural da ESALQ.

**** Departamento de Matemática e Estatística da ESALQ. 
Quando uma emulsão de carne estável é obtida, não há, por ocasião do seu processamento térmico, separação da gordura dispersa. A estabilidade da massa é influenciada por diversos fatores, revistos por MACKENZIE (1966) e por SAFFLE (1968). Alguns desses fatores se relacionam com os ingredientes cárneos empregados: tecido muscular (fonte de proteínas solúveis em soluções salinas), gordura a ser emulsionada. Certos ingredientes não cárneos podem melhorar a estabilidade, como é o caso de sólidos do leite e de proteínas da soja. Outros aspectos importantes incluem ainda: as características do equipamento empregado na obtenção da emulsão, a sequência das etapas e a temperatura final da massa na elaboração desta e as condições do processamento térmico.

Entre os fatores que se relacionam com a ação estabilizante de proteínas de origem muscular incluem-se $o \mathrm{pH}$ da massa e 0 momento de adição do sal comum à carne. SWIFT e SULZBACHER (1963) verificaram que uma elevação do $\mathrm{pH}$ de 5,5 para 6,5 resultava em um aumento da quantidade de óleo emulsionada por proteínas (solúveis em $\mathrm{NaC1} 0,6 \mathrm{M}$ ) do tecido muscular de bovinos. SAFFLE e GALBRAITH (1964) demonstraram que a extração de proteínas musculares por $\mathrm{NaC}$ a $3 \%$ aumentava quando o $\mathrm{pH}$ passava de 5,5 para 6,5. Segundo Hamm, citado por WILSON (1960 a), a adição de fosfatos pode contribuir para a estabilidade da emulsão de carne, devido à elevação do $\mathrm{pH}$ e/ou à capacidade de ligar-se a ions metálicos. Por outro lado, o desenvolvimento da coloração característica de carne curada e aquecida, resultante da adição de nitrito de sódio, é desfavorecido por uma excessiva elevação do pH (WILSON, 1960 b); o emprego de agentes redutores, como o ascorbato de sódio, e da deltalactona do ácido glucônico favorece a chamada reação de cura. No caso desta última substância, sua ação é explicada pela produção de ácido glucônico, com consequente redução do $\mathrm{pH}$, durante o processamento térmico (SAIR, 1965). ACTON e SAFFLE (1969) obtiveram um aumento da capacidade de emulsionar gordura da carne bovina com a adição de sal comum e gelo 12-24 horas antes da elaboração da emulsão.

0 presente trabalho foi desenvolvido com o objetivo de estudar a influência de alguns fatores (ingrediente de origem muscular, $\mathrm{pH}$ da carne e da emulsão e adição prévia de sal comum à carne) sobre a estabilidade de emulsões elaboradas com tecido muscular bovino e tecido adiposo suino em um pequeno triturador de alimentos tipo «cutter», de mesa, com capacidade para cerca de $2 \mathrm{~kg}$ de massa. Partiu-se do pressuposto de que a elaboração de pequenas quantidades de emulsão, em laboratório, pode ser de grande valia para o ensino da ciência e tecnologia da carne, assim como para o desenvolvimento de certos tipos de pesquisa.

\section{MATERIAIS E MÉTODOS}

Ingredientes. Como ingredientes cárneos, foram utilizados = carne bovina magra de animais de açougue, obtida da paleta (patinho da paleta) (Ensaio I), do pescoço (Ensaio II) e gordura suina (toicinho). A carne 
bovina desossada, separada de gordura, foi moida 3 vezes e deixada em refrigerador (cerca de $0^{\circ} \mathrm{C}$ ) por $16-20$ horas. No Ensaio I, cinco repetições foram realizadas para cada tratamento ( $A, B, C$ e $D)$, a cada repetição correspondendo a carne de um animal diferente: portanto 20 animais estiveram envolvidos. No Ensaio II, carne de 5 animais foi utilizada, correspondendo a cada um deles uma repetição de dois tratamentos ( $E$ e $F$ ). 0 toicinho, removido a pele e o tecido muscular acompanhante, foi moido 3 vezes e congelado $\left(-27^{\circ} \mathrm{C}\right)$ em porções de cerca de $300 \mathrm{~g}$, acondicionadas em folhas de alumínio. As formulações empregadas podem ser assim resumidas: carne bovina magra, 80\%; gordura suina, 20\%; mistura geloágua, na proporção de 1:1 em peso, 30\% (Ensaio I) e 25\% (Ensaio II); sal comum refinado, 2,5\%; condimentos, 0,3\%; nitrito de sódio, $0,015 \%$; ácido ascórbico, 0,03\% (Ensaio II); fosfato de sódio dibásico, 0,25\% (Ensaio I, Tratamento D; e Ensaio II, Tratamento F); delta-lactona do ácido glucônico, 0,25\% (Ensaio II, Tratamento E). Os 4 últimos ingredientes foram adicionados dissolvidos em $30-40 \mathrm{ml}$ de água, a qual foi descontada no peso da mistura gelo-água.

Preparo das emulsões - Porções de massa de 1900 a 2000 g foram preparadas conforme segue:

Ensaio I. Trafamento A: a carne bovina, transferida do refrigerador para o «cutter» de mesa (Hobart, Modelo 84142), foi adicionada de sal comum, condimentos, nitrito de sódio e um terço da mistura gelo-água, seguindo-se = trituração por 1 minuto, adição da gordura suina (descongelada e cortada em cubos de cerca de $2,5 \mathrm{~cm}$ de lado) e de um terço da mistura gelo-água, trituração por 1 minuto, adição do restante da mistura gelo-água e trituração por 4 minutos. A temperatura final da massa foi determinada com auxílio de um termômetro metálico, de disco.

Tratamento B: diferiu do anterior apenas quanto ao $\mathrm{pH}$ da carne bovina utilizada, superior e inferior a 6,00, respectivamente.

Tratamento $\mathbf{C}$ : neste caso o sal comum e os condimentos foram adicionados à carne bovina moida, 16-18 horas antes da elaboração da emulsão.

Tratamento D: diferiu do anterior pela adição, à carne, 16-18 horas artes do preparo da massa, e juntamente com o sal comum e os condimentos, de fosfato de sódio dibásico.

Ensaio II. Tratamento E: a carne bovina moida, adicionada (16-18 horas antes do preparo da emulsão) de sal comum e condimentos, foi transferida para o «cutter» e, então, adicionada de nitrito e um terço da mistura gelo-água, seguindo-se: trituração por 0,5 minuto, adição de um terço da mistura gelo-água, trituração por 0,5 minuto, adição da gordura suina (descongelada e cortada em cubos de cerca de $2,5 \mathrm{~cm}$ de lado) e do restante da mistura gelo-água, trituração por 3 minutos, adiçãú do ácido ascórbico, trituração por 2 minutos. 
Tratamento F: neste caso, fosfato de sódio dibásico foi adicionado à carne, juntamente com o sal comum e os condimentos (16-18 horas antes da elaboração da massa) e, no preparo da emulsão (conforme descrito para o tratamento E), a delta-lactona do ácido glucônico foi adicionada à massa antes do último minuto de trituração.

Processamento térmico. Porções de cerca de $300 \mathrm{~g}$ das emulsões cruas foram transferidas para latas $\mathrm{N}^{\circ} 2$ e processadas pelo calor em forno elétrico à temperatura de cerca de $93^{\circ} \mathrm{C}$, até que o centro geométrico da massa estivesse a $70^{\circ} \mathrm{C}$. Após resfriamento em água corrente, as peças, removidas das latas, foram acondicionadas em folhas de alumínio e congeladas $\left(-27^{\circ} \mathrm{C}\right)$ para posterior análise.

Análise química. $O$ teor de umidade da carne bovina magra foi determinado por secagem em estufa a $100-102^{\circ} \mathrm{C}$ (A.M.I., 1954); o teor de proteína bruta do mesmo material foi determinado conforme A.M.I. (1954). $\mathrm{O} \mathrm{pH}$ da carne magra e das emulsões cruas e cozidas foi determinado em uma suspensão do material em igual peso de água destilada, com auxílio de um potenciômetro Beckman Zeromatic.

Teste de estabilidade. As emulsões, logo após o seu preparo no «cutter», foram testadas quanto à estabilidade pelo método de SAFFLE ef al. (1967), usando-se frescos Paley com escala de 0 a 50\% e uma força centrífuga equivalente a $860 \times \mathrm{G}$.

Análise sensorial. Após descongelamento, cada porção da emulsão cozida foi dividida ao meio longitudinalmente e a superfície recém-exposta foi submetida à avaliação visual da textura e da cor por um grupo de 5 provadores semi-treinados. Três conjuntos de amostras, contendo cada um deles todos os tratamentos do Ensaio I, foram examinados sob uma mistura de luz natural e fluorecente. Foi utilizado o teste de ordenação segundo a preferência (KRAMER, 1956) e os valores médios das somas relativas aos três conjuntos analisados com auxílio da tabela de KAHAN et al. (1973).

\section{Análise estatística dos resultados}

Os dados obtidos foram analisados pelo teste $F$ (modelo de experimentos completamente casualizados) e as médias comparadas pelo teste de Tukey (GOMES, 1970), com exceção dos valores correspondentes à análise sensorial.

\section{RESULTADOS E DISCUSSAOO}

Composição química da carne magra. Os teores de umidade e de proteína da carne magra, assim como a relação umidade/proteína e o $\mathrm{pH}$, correspondentes aos vários tratamentos dos Ensaios I e II, acham-se no Quadro 1. Não foi encontrada diferença significativa entre os teores de umidade, mas a carne proveniente da região do pescoço (Tratamentos 
E-F) apresentou um teor de proteína superior e uma relação umidade/proteína inferior, significativamente, aos valores correspondentes da carne obtida da paleta (Tratamentos A, ---D), com a exceção do tratamento D. As médias dos tratamentos relativos ao Ensaio I não diferiram significativamente, indicando, assim, uma composição homogênea da carne magra, quanto a umidade e proteína. No caso do tratamento $B$, foi propositadamente utilizada carne magra com $\mathrm{pH}$ superior a 6,00 , não tendo sido constatadas diferenças significativas entre as médias correspondentes aos demais tratamentos, quanto à propriedade em questão.

Variação do pH no processamento. A emulsão obtida no Ensaio I com carne apresentando $\mathrm{pH}$ superior a 6,00 (Tratamento B), após processamento térmico, diferiu significativamente daquelas elaboradas com carne apresentando $\mathrm{pH}$ inferior a 6,00 (Tratamentos $\mathrm{A}$ e $\mathrm{C}$ ), quanto à acidez (Quadro 2); a adição de fosfato de sódio dibásico à carne (Tratamento D) resultou em emulsão cozida com $\mathrm{pH}$ significativamente superior aos observados para os tratamentos sem fosfato, com exceção do Tratamento B. 0 Quadro 3 e a Figura 1 mostram a variação do $\mathrm{pH}$ nas diferentes etapas do processamento correspondente ao Ensaio II. Pode-se inicialmente notar que a adição de sal comum e fosfato de sódio dibásico (Tratamento $\mathrm{F}$ ) elevaram significativamente $o \mathrm{pH}$ da carne, antes e após a obtenção da emulsão. A adição de ácido ascórbico à emulsão não reduziu significativamente o pH da mesma (Tratamento $\mathrm{E}$ e F), o mesmo ocorrendo com a adição de delta-lactona do ácido glucônico (Tratamento F). Após o processamento térmico, não foi observada diferença significativa entre os tratamentos E e F; portanto, a ação acidulante da lactona, no processamento pelo calor (SAIR, 1965), compensou a ação alcalinizante do fosfato, observada após sua adição à carne e refletida, inclusive, no pH relativamente elevado da massa cozida correspondente ao tratamento D (Ensaio I).

Temperatura das emulsões no "cutter». Tanto no Ensaio I como no II não foram constatadas diferenças significativas entre as temperaturas finais, no «cutter», das emulsões correspondentes aos vários tratamentos. (Quadro 4). Conforme recomendado por MACKENZIE (1966), entre outros autores, a temperatura foi controlada de modo que seus valores não ultrapassassem $15^{\circ} \mathrm{C}$.

Estabilidade das emulsões. No teste de SAFFLE et al. (1967), pode-se notar claramente (Quadro 5) que, no Ensaio I, apenas quando o pH da carne era superior a 6,00 ou quando fosfato de sódio dibásico era adicionado à mesma, eram obtidas emulsões estáveis (Tratamentos B e D, respectivamente). A adição prévia de sal comum à carne (Tratamento $\mathrm{C}$ ) não resultou em emulsão estável, embora se possa admitir que essa prática tenha contribuido para a estabilidade observada no caso do Tratamento $\mathrm{D}$, pois houve diferença significativa entre as quantidades de gordura separadas nos Tratamentos A e C. No Ensaio II, resultados semelhantes foram obtidos, com os tratamentos $\mathrm{E}$ e $\mathrm{F}$, semelhantes aos $\mathrm{C}$ e $\mathrm{D}$, respectivamente; neste caso, porém, $0 \mathrm{pH}$ da emulsão com fosfato, pro- 
cessada pelo calor, foi controlado pelo emprego de acidulante (Quadro 3 e Figura 1). Nas condições do presente trabalho, verificou-se, portanto, que o $\mathrm{pH}$ da carne ou da emulsão antes do seu processamento térmico foi fator limitante para a estabilidade dos sistemas, o que pode ser explicado pela sua influência sobre a solubilização de proteínas musculares na presença de sal comum e sobre a capacidade de emulsionar gordura dessas proteínas (SWIFT e SULZBACHER, 1963; SAFFLE e GALBRAITH, 1964). Não se pode, entretanto, excluir a possibilidade da obtenção de emulsões estáveis com o equipamento em estudo, pelo emprego de outras recursos tais como $=$ uso de outros fosfatos estabilizantes, de concentrados protêicos ou proteínas isoladas da soja, de sólidos do leite desnatado, de carne no estado «ante rigor, etc.

Características sensoriais das emulsões. $\mathrm{Na}$ análise sensorial das emulsões cozidas correspondentes ao Ensaio I (Quadro 6), o Tratamento $\mathrm{B}$, quanto à textura, foi significativamente superior aos demais e o A, inferior; a cor foi prejudicada pela adição de fosfato de sódio dibásico (Tratamento D). No Ensaio II, embora não tivesse sido realizada uma avaliação sensorial com um grupo de provadores, pode ser observado um desenvolvimento satisfatório da coloração em ambos os tratamentos (E e F) e a diferença de textura, entre ambos, foi evidente. No caso do Tratamento E, assim como para os Tratamentos A e C (Ensaio I), a textura se apresentou inacentável, sendo visíveis numerosas bolsas de gordura, observações essas que corresponderam aos resultados obtidos no teste de estabilidade.

\section{CONCLUSÕES} clusões:

Os resultados do presente trabalho permitem chegar às seguintes con-

1) Utilizando-se tecido muscular bovino, como fonte única de proteínas estabilizantes, podem ser obtidas, em laboratório, pequenas quantidades de emulsão de carne estável, com o equipamento testado.

2) Nas condições do presente trabalho, entre os parâmetros que influem sobre a estabilidade do sistema, o $\mathrm{pH}$ da carne ou da emulsão constitui fator limitante, podendo ser de grande valia a utilização combinada de aditivos modificadores da acidez.

3) Nas condições do presente trabalho, a prática de adição prévia de sal comum à carne magra, refrigerada e no estado «post rigor», com pH inferior a 6,00, não é suficiente para a obtenção de emulsões estáveis.

4) 0 teor de proteína bruta da carne magra proveniente da região do pescoço parece ser superior ao da carne magra obtida da paleta (patinho da paleta), o inverso ocorrendo com a relação umidade/proteína. 


\section{SUMMARY}

\section{STABILITY OF MEAT EMULSIONS PREPARED IN SMALL QUANTITIES, UNDER LABORATORY CONDITIONS}

The influence of some factors on the stability of meat emulsions prepared with a table size meat cutter (Hobart 84142) was studied. Bovine lean meat (fresh, postrigor) from different carcass lacations was used as the only source of stabilizing proteins, and pork fat was emulsified according to common industrial formulations and practices. Stable and unstable systems were obtained, the $\mathrm{pH}$ of meat or emulsions being a limiting factor. Preblending of the meat (ground beef plus common salt) decreased the amount of fat separated, but was not enough to prevent emulsions breakdown.

\section{LITERATURA CITADA}

ACTON, J. C. \& R. L. SAFFLE. 1969. Preblencied and prerigor meat in sausage emulsions. Food Technology 23 : 367-371.

A. M. I. 1954. Laboratory Methods of the Meat Industry. American Meat Insitute, Chicago, IIl.

BECHER, P. 1965. Emulsions: Theory and Practice. 2. ${ }^{7}$ Ed. Reinhold Publishing Corporation, Nova York, N. Y.

GOMES, F. P. 1970. Curso de Estatística Experimental. 4.* Ed. Livraria Nobel, São Paulo, SP.

KAHAN, G., D. COOPER, A. PAPAVASILIOU e A. KRAMER. Expanded tables for determining significance of differences for ranked data. Food Technology 27 : 63-69.

KRAMER, A. 1956. A quick, rank test for significance of differences in multiple comparisons. Food Techonology $10: 391-392$.

MACKENZIE, D. S. 1966. Prepared Meat Product Manufacturing. American Meat Institute, Chicago, Ill.

SAFFLE, R. L. 1968. Meat emulsions. Advances in Food Research 16 : 105-160.

SAFFLE, R. L., J. A. CHRISTIAN, J. A. CARPENTER \& S. B. ZIRKLE. 1967. Rapid method to determine stability of sausage emulsions and effect of processing temperatures and humidities. Food Technology 21 : 784-788.

SAFFLE, R. L. \& J. W. GALBRAITH. 1964. Quantitative determination of salt-soluble protein in various types of meat. Food Technology $18: 1943-1944$.

SAIR, L. 1965. Research and cure color applications in sausage. Proceedings of the Meat Industry Research Conference. pp. 113-115.

SWIFT, C. E. 1965. The emulsifying properties of meat proteins. Proceedings of the Meat Industry Research Conference. pp. 78-93.

SWIFT, C. E. \& W. L. SULZBACHER. 1963. Factors affecting meat proteins as emulsion stabilizers. Food Technology 17 : 224-226.

WILSON, G. D. 1960a. Sausage products. Em: A. M. I. F. The Science of Meat and Meat Products. W. H. Freeman, São Francisco, Cal. pp. 349-372.

WILSON, G. D. 1960b. Meat curing. Em: A. M. I. F. The Science of Meat and Meat Products. W. H. Freeman, São Francisco, Cal. pp. 328-348. 
Quadro 1: Composição química da carne magra: valores médios dos teores de umidade (U), proteina (P.), da relação U/P e do pH, e resumo da análise estatística.

\begin{tabular}{|c|c|c|c|c|c|c|c|c|}
\hline \multirow{2}{*}{ Valores } & \multicolumn{4}{|c|}{ Ensaio 1} & \multirow{2}{*}{$\frac{\text { Ensaio II }}{E-F}$} & \multirow{2}{*}{$\begin{array}{c}\text { Teste } \\
\text { F }\end{array}$} & \multirow{2}{*}{$\begin{array}{l}\text { CV } \\
(\%)\end{array}$} & \multirow{2}{*}{$\begin{array}{c}\Delta \\
(P<0,05)\end{array}$} \\
\hline & A & B & C & D & & & & \\
\hline Umidade (\%) & 75,88 & 75,76 & 75,84 & 75,85 & 74,69 & NS & 0,92 & - \\
\hline Proteina (\%) & 20,03 & 19,84 & 19,83 & 20,28 & 21,20 & $4,84 * *$ & 2,86 & 1,10 \\
\hline Relação U/P & 3,79 & 3,82 & 3,83 & 3,75 & 3,53 & $5,53 * *$ & 3,15 & 0,22 \\
\hline pH & 5,70 & 6,25 & 5,71 & 5,78 & 5,57 & $13,81 * *$ & 2,70 & 0,30 \\
\hline
\end{tabular}

Quadro 2: Valores médios do pH das emulsões (Ensaio 1), após processamento térmico, e resumo da análise estatística.

\begin{tabular}{l|c|c|c|c}
\hline \multirow{2}{*}{ Valores } & \multicolumn{4}{|c}{ Ensaio I } \\
\cline { 2 - 5 } & A & B & C & D \\
\hline pH & 6,19 & 6,52 & 6,18 \\
\hline Teste $F$ & \multicolumn{4}{|c}{$10,79^{*} *$} \\
\hline $\mathrm{CV}(\%)$ & 1,96 \\
\hline$\Delta(P<0,05)$ & 0,23 \\
\hline
\end{tabular}


Quadro 3:: Valores médios do pH das emulsões (Ensaio II) nas diferentes etapas do processamento, e resumos das análises estat/sticas.

\begin{tabular}{|c|c|c|}
\hline \multirow{2}{*}{ Etapas } & \multicolumn{2}{|c|}{$\mathbf{p H}$} \\
\hline & Tratamento $\mathrm{E}$ & Tratamento $F$ \\
\hline a) Carne magra & 5,57 & 5,57 \\
\hline b) Carne + sal comum & 5,84 & - \\
\hline b) Carne + sal comum + fosfato & - & 6,20 \\
\hline Teste F & \multicolumn{2}{|c|}{$18,96 * *$} \\
\hline CV $(\%)$ & \multicolumn{2}{|c|}{2,74} \\
\hline$\Delta(P<0,05)$ & \multicolumn{2}{|c|}{0,27} \\
\hline \multirow{2}{*}{ Etapas } & \multicolumn{2}{|c|}{ pH } \\
\hline & Tratamento $\mathbf{E}$ & Tratamento $\mathbf{F}$ \\
\hline c) Emulsão & 5,83 & 6,12 \\
\hline d) Emulsão + ácido ascórbico & 5,77 & 6,09 \\
\hline $\begin{array}{l}\text { e) Emulsão + ácido ascórbico + } \\
\text { lactona }\end{array}$ & - & 5,98 \\
\hline $\begin{array}{l}\text { f) Emulsão após processamento } \\
\text { térmico }\end{array}$ & 6,17 & 6,09 \\
\hline Teste $F$ & & \\
\hline CV $(\%)$ & & \\
\hline$\Delta(P<0,05)$ & & \\
\hline
\end{tabular}

Quadro 4: Valores médios da temperatura final das emulsões no "cutter", e resumo das análises estatisticas.

\begin{tabular}{|c|c|c|c|c|c|c|}
\hline \multirow{2}{*}{ Valores } & \multicolumn{4}{|c|}{ Ensaio 1} & \multicolumn{2}{|c|}{ Ensaio 11} \\
\hline & $\mathbf{A}$ & B & C & D & $\mathbf{E}$ & $\boldsymbol{F}$ \\
\hline Temperatura $\left({ }^{\circ} \mathrm{C}\right)$ & $12 ; 60$ & 13,50 & 13,60 & 14,30 & 10,60 & 11,70 \\
\hline Teste F & \multicolumn{4}{|c|}{1,36 NS } & \multicolumn{2}{|c|}{1.42} \\
\hline CV $(\%)$ & \multicolumn{4}{|c|}{9,92} & \multicolumn{2}{|c|}{13,09} \\
\hline
\end{tabular}


Quadro 5: Estabilidade da emulsão $1 \%$ gordura separada), e resumo da análise estatistica. 0 sinal (-) indica quantidades de gordura menores que $0,5 \%$.

\begin{tabular}{l|c|c|c|c|c|c}
\hline \multirow{2}{*}{ Repetições } & \multicolumn{5}{|c|}{ Ensaio I } & \multicolumn{2}{c}{ Ensaio II } \\
\cline { 2 - 7 } & A & B & C & D & E & F \\
\hline 1 & 6,50 & - & 5,25 & - & 2,50 & - \\
2 & 7,50 & 2,50 & 4,00 & - & 0,50 & - \\
3 & 8,50 & - & 5,00 & - & 3,25 & - \\
4 & 9,00 & - & 4,00 & - & 6,25 & 1,25 \\
5 & 8,50 & - & 7,25 & - & 5,50 & - \\
\hline Médias & 8,00 & - & 5,10 & - & 3,60 & - \\
\hline A X C & \multicolumn{6}{|c|}{ CV $=9,58 \%$} \\
\hline
\end{tabular}

Quadro 6 : Médias das somas das classificações obtidas pelos tratamentos (Ensaio I) na avaliação da textura e da cor da emulsão cozida, e resumo da análise estatística.

\begin{tabular}{l|c|c|c|c}
\hline Textura & B & D & C & A \\
& $6,67^{*}$ & 8,33 & 15,33 & $19,67^{*}$ \\
\hline Cor & A & B & C & D \\
& $6,33^{*}$ & 11,00 & 13,67 & $19,00 *$ \\
\hline
\end{tabular}

Limites de significância (KAHAN ot al., 1973):

$$
\begin{array}{rr}
P<0,05=7-18 & P<0,01=6-19 \\
8-17 & 7-18
\end{array}
$$




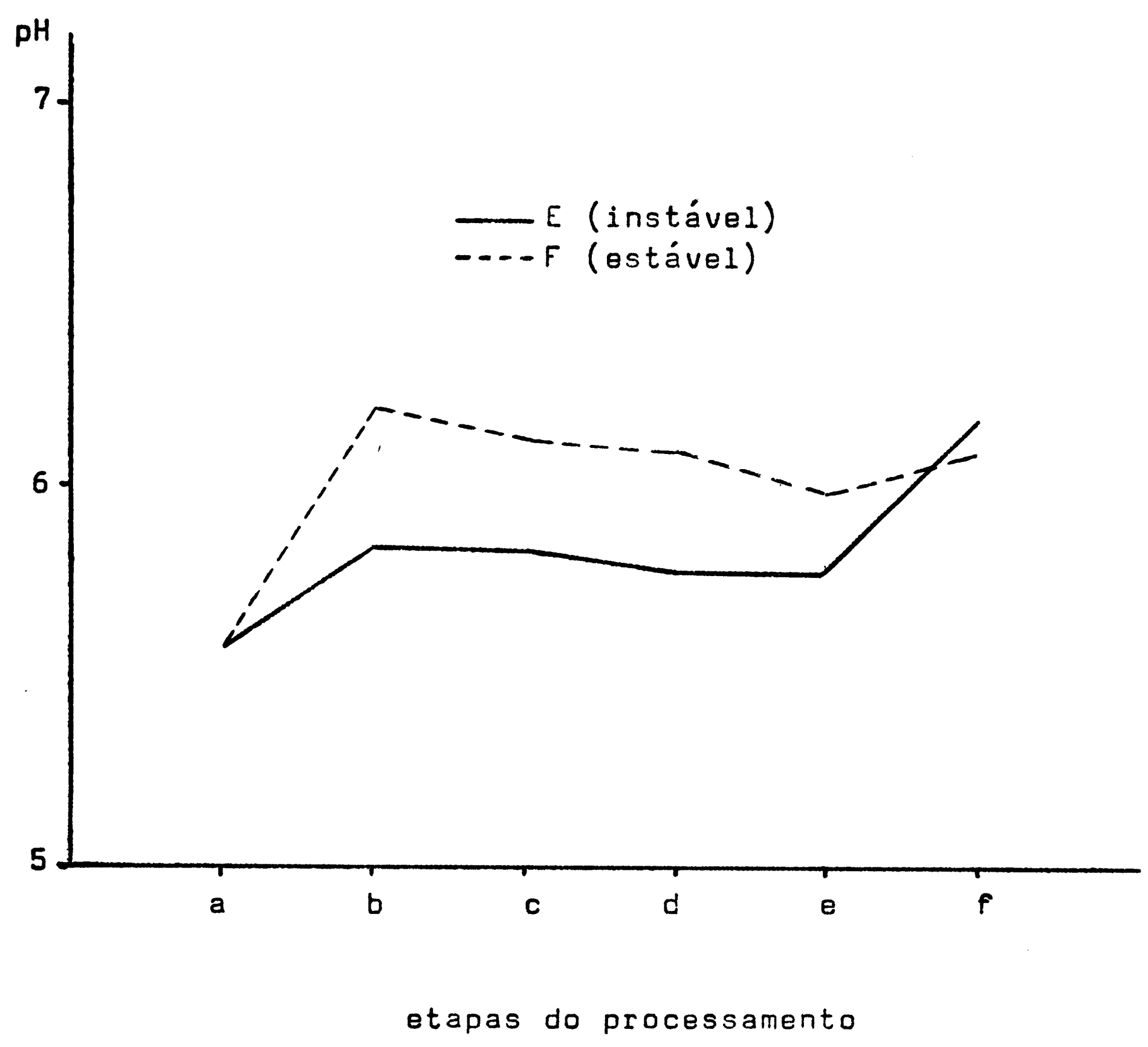

FIGURA 1 - Variação do $\mathrm{pH}$ durante o processamento no Ensaio II (Tratamentos E e F). Etapas a..... (conforme Quadro III). 
